\title{
Análisis espectral y dispersión superficial de detritos suspendidos en la Bahía de Banderas mediante imágenes de satélite
}

\author{
Carlos González-Luna*,** \\ Anatoliy Filonov* \\ Omar Mireles*,** \\ Iryna Tereshchenko*
}

Recibido 8 de septiembre de 2018; aceptado 7 de noviembre de 2018

\begin{abstract}
Thanks to colorimetric techniques and unsupervised classification methods, can be vectorized and ploted the pollutants discharged evolution in the sea with respect to time and Landsat space, which, in practice, lowers the cost of research and allows for greater spatio-temporal coverage. This paper presents the case study of Bahía de Banderas, Jalisco-Nayarit, Mexico, where the detritus discharge by the Ameca River was studied in the period 2006-2014 through a combined product of LandSat and Modis images and with the analysis of the spectral signatures of the different bands that present these satellites, the percentages of the dissolved organic matter in the feathers are inferred.
\end{abstract}

Key words: remote sensing, debris, non-supervised classification, colorimetry, landsat, modis.

\section{Resumen}

Gracias a técnicas de colorimetría y métodos de clasificación no supervisada, pueden ser vectorizada y trazada la evolución de contaminantes vertidos en el mar con respecto al tiempo y al espacio, lo que, en la práctica, abarata el costo de investigación

* Maestría en Ciencias en Hidrometeorología, Centro Universitario de Ciencias Exactas e Ingeniería, Universidad de Guadalajara, Blvd. Gral. Marcelino García Barragán 1421, Olímpica, 44430, Guadalajara, Jalisco, México, correo electrónico: geocarlosdeluna@gmail.com

** Escuela Militar de Especialistas de la Fuerza Aérea, Avenida Aviación s/n, Jardines de Nuevo México, 45200, Zapopan, Jalisco, México. 
y permite tener una mayor cobertura espacio-temporal. Este trabajo presenta el caso de estudio de Bahía de Banderas, Jalisco-Nayarit, México, donde se estudió el vertido de detritos por el río Ameca en el periodo 2006-2014 a través de un producto combinado de imágenes LandSat y Modis y con el análisis de las firmas espectrales de las diferentes bandas que presentan estos satélites se infiere los porcentajes de la materia orgánica disuelta en las plumas.

Palabras clave: percepción remota, detritos, clasificación no supervisada, colorimetría, landsat, modis.

\section{Resumo}

Graças a técnicas de colorimetria e métodos de classificação não supervisionados, podem ser vetorizada e observada a evolução de contaminantes descargas no mar com respeito ao tempo e ao espaço, o que na prática, reduz o custo de investigação e permite ter uma maior cobertura espaço-temporal. Este trabalho apresenta o caso de estudo de Bahía de Banderas, Jalisco-Nayarit, México, onde se estudou a descarga de detritos no rio Ameca no período 2006-2014 através de um produto combinado de imagens LandSat e Modis e, com a análise das assinaturas espectrais das diferentes bandas que apresentam estes satélites, se infere os percentuais da matéria orgânica dissolvida nas plumas.

Palavras chave: percepção remota, detritos, classificação não supervisionada, colorimetria, landsat, modis.

\section{Introducción}

El Río Ameca es uno de los escurrimientos más importantes que desemboca en la Bahía de Banderas, su cuenca tiene una extensión territorial de $12214 \mathrm{~km}^{2}$ y una precipitación normal anual en el periodo 1971-2000 de $1020 \mathrm{~mm}$ (INEGI, 2004). Su escurrimiento natural medio superficial total es de $2235 \mathrm{hm}^{3} /$ año (Comisión Nacional del Agua-CNA).

Las aguas de este escurrimiento contienen residuos provenientes del lavado continental (rocas, sedimentos, materia orgánica, entre otros) y con base a lo observado en las imágenes de satélite, estos residuos se esparcen al llegar a la bahía formando las plumas de detritos suspendidos (agua turbia) donde el comportamiento y concentración de estas partículas suspendidas varía en todo el año y su tamaño está relacionado con el periodo de lluvias.

La concentración del total de contaminantes y sedimentos suspendidos provenientes del lavado continental y materia orgánica (detritos), constituye uno de los parámetros de calidad de agua más importantes (Rodríguez-Guzmán et al., 2009), 
principalmente por estar relacionados a la producción y flujo de metales pesados y microcontaminantes (Ekercin, 2007).

Estos sedimentos consisten en partículas suficientemente finas para ser transportadas en suspensión por el agua en movimiento (Campbell, 2007), como lo son la arcilla, el limo y la arena (Miller et al., 2004). Además de afectar la calidad del agua, los detritos son indicativo de problemas de erosión en las cuencas hidrográficas. Más aún, el estudio de esta materia, principalmente en regiones costeras, tiene una gran importancia ecológica ya que las altas concentraciones de detritos en zonas costeras pueden afectar la productividad del fitoplancton y de la vegetación acuática sumergida, el crecimiento de corales, la dinámica de nutrientes, y el transporte de contaminantes y otros materiales (Miller et al., 2004).

Derivado a las problemáticas anteriores es indispensable contar con un análisis de la dinámica de dispersión de los residuos en la Bahía de Banderas que funcione también como un insumo a los tomadores de decisiones en el ámbito social, turístico y medio ambiental.

Existen varias vías para estudiar la dispersión espacial de las plumas de detritos en los cuerpos de agua: Modelos numéricos, mediciones in situ, Teledetección (Geomática), entre otros. En este artículo se aborda la problemática mediante técnicas de Geomática que en términos generales es la detección a distancia (percepción remota) de las características y cambios que se producen en la superficie de la Tierra.

La identificación de éstas plumas, las variaciones en su extensión, patrones de dispersión y sus tasas de mezcla con aguas oceánicas es crítica en todos los aspectos de la oceanografía regional y de la plataforma continental (Lohrenz et al., 1990).

La teledetección ha demostrado tener un potencial elevado en el monitoreo y seguimiento de fenómenos como la dispersión de residuos y contaminantes. La percepción remota de recursos naturales se basa en un sistema de adquisición de datos a distancia y que está basado en las propiedades de la radiación electromagnética y en su interacción con los materiales de la superficie terrestre (Romero, 2006).

Por lo anterior, para este trabajo de tesis, se analizó el comportamiento de la dinámica superficial y dispersión de los detritos vertidos por el Río Ameca en la Bahía de Banderas mediante técnicas de percepción remota utilizando un producto combinado de imágenes LANSAT y MODIS en el periodo 2006-2014.

\section{Area de estudio}

El área de estudio es la Bahía de Banderas, la cual se localiza en la costa occidental de México (Figura 1) y constituye el límite sur del Golfo de California en su parte continental, abarcando parte de los estados de Jalisco y Nayarit. Geográficamente, la bahía está ubicada entre los $20^{\circ} 25^{\prime}$ y $20^{\circ} 47^{\prime}$ de latitud norte y los $105^{\circ} 41^{\prime}$ y $105^{\circ}$ $25^{\prime}$ de longitud oeste (Figura 2). 


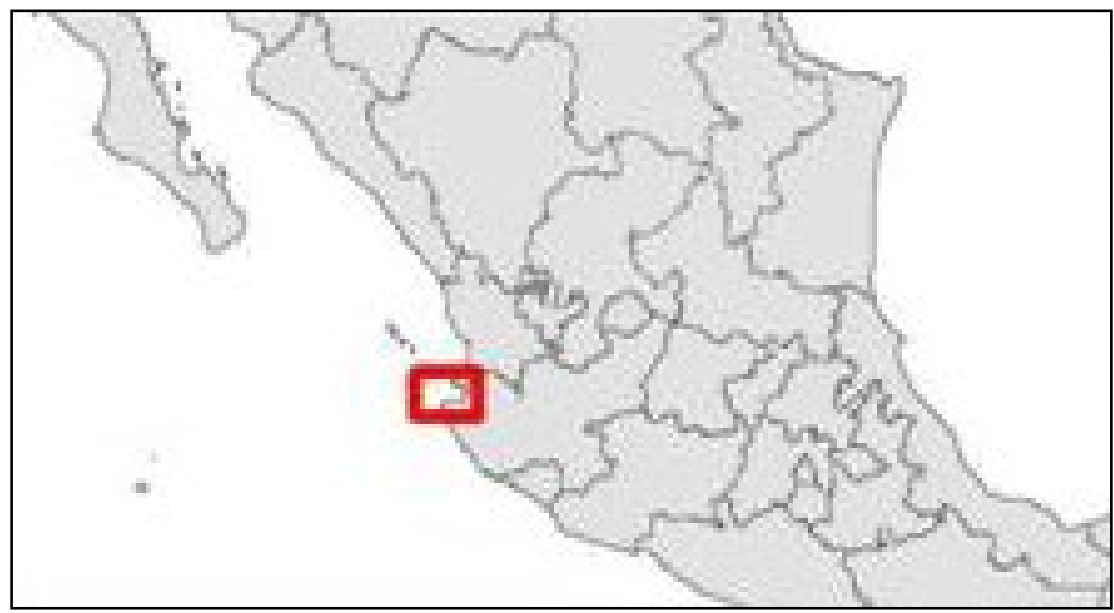

Figura 1. Ubicación de la Bahía de Banderas, México.

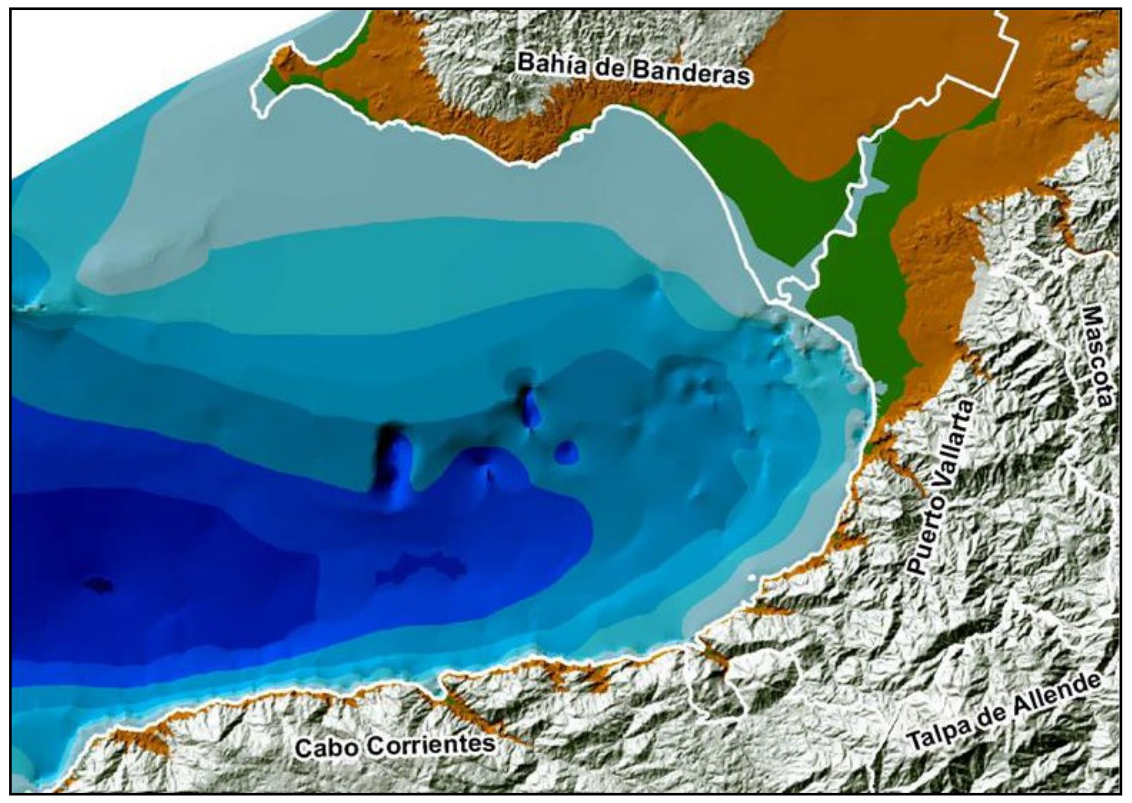

Figura 2. Situación geográfica de la Bahía de Banderas, México. 


\section{Materiales y métodos}

La presente investigación se realizó con la finalidad de abundar y documentar una metodología sobre la aplicación de la teledetección a problemáticas oceanográficas y costeras. En este sentido, y debido a la problemática de residuos suspendidos que presenta la Bahía de Banderas se documentó la serie de tratamientos necesarios tanto para extraer de cada imagen satelital la porción de la bahía con detritos suspendidos como para registrar su firma espectral con la intensión de que la metodología sea reproducible en otros océanos del planeta.

Para el procesamiento y análisis de la información que se aborda en este artículo, se utilizó el software de ArcGis empleando el módulo de Raster Processing y Multivariate. Se analizaron un total de 194 imágenes de satélites, 85 del satélite Modis y 109 del satélite Landsat. De las 109 imágenes Landsat, 6 corresponden a Landsat 5, 84 a Landsat 7 y 19 a Landsat 8.

Para la identificación de los sedimentos suspendidos en la Bahía se utilizó el método de clasificación no supervisada y validación visual por cada imagen ya que por motivo de tiempos no fue posible realizar una corrección radiométrica completa que estandarizara a todas las escenas. En compensación a lo anterior, se empleó la parcela de control en donde se observa la variación radiométrica entre los distintos sensores con el objetivo de ajustar los rangos de las categorías (con apoyo de la validación visual) para cada sensor y garantizar que sean comparables.

También, se tomaron muestras espectrales de distinta coberturas conocidas que no presenten cambio en el tiempo en las distintas escenas de un mismo sensor para ajustar o escalar los números digitales (ND). Finalmente se realizaron estadísticas para cada categoría y sensor en donde se observa que el rango de cada categoría se mantiene (Tablas 1 y 2).

Tabla 1

Variación de los promedios en ND por categoría y banda del sensor Modis

\begin{tabular}{|c|l|c|c|c|}
\hline \multirow{3}{*}{ CATEGORIA } & \multicolumn{4}{|c|}{ MODIS } \\
\cline { 2 - 5 } & \multicolumn{1}{|c|}{ BANDA } & $\begin{array}{c}\text { Promedio } \\
\text { General }\end{array}$ & $\begin{array}{c}\text { Promedio } \\
\text { Inferior }\end{array}$ & $\begin{array}{c}\text { Promedio } \\
\text { superior }\end{array}$ \\
\hline \multirow{3}{*}{$\mathbf{1}$} & Rojo & 25.36 & 18.08 & 32.65 \\
\cline { 2 - 5 } & Verde & 40.51 & 32.73 & 48.30 \\
\cline { 2 - 5 } & Azul & 36.72 & 30.05 & 43.39 \\
\hline \multirow{3}{*}{2} & Rojo & 44.01 & 34.38 & 53.64 \\
\cline { 2 - 5 } & Verde & 58.01 & 49.10 & 66.92 \\
\cline { 2 - 5 } & Azul & 48.30 & 40.34 & 56.26 \\
\hline \multirow{3}{*}{3} & Rojo & 83.49 & 57.51 & 109.46 \\
\cline { 2 - 5 } & Verde & 83.72 & 66.89 & 100.54 \\
\cline { 2 - 5 } & Azul & 60.00 & 46.76 & 73.24 \\
\hline
\end{tabular}


Tabla 2

Variación de los promedios en ND por categoría y banda de los sensores Landsat 5, 7 y 8

\begin{tabular}{|c|c|c|c|c|c|c|c|c|c|c|}
\hline \multirow[b]{2}{*}{ CATEGORIA } & \multirow[b]{2}{*}{ BANDA } & \multicolumn{3}{|c|}{ LANDSAT 5} & \multicolumn{3}{|c|}{ LANDSAT 7} & \multicolumn{3}{|c|}{ LANDSAT 8} \\
\hline & & $\begin{array}{c}\text { Promedio } \\
\text { General } \\
\end{array}$ & $\begin{array}{l}\text { Promedio } \\
\text { Inferior }\end{array}$ & $\begin{array}{c}\text { Promedio } \\
\text { superior }\end{array}$ & $\begin{array}{c}\text { Promedio } \\
\text { General } \\
\end{array}$ & $\begin{array}{l}\text { Promedio } \\
\text { Inferior }\end{array}$ & $\begin{array}{c}\text { Promedio } \\
\text { superior }\end{array}$ & \begin{tabular}{|c|} 
Promedio \\
General \\
\end{tabular} & \begin{tabular}{|c|}
$\begin{array}{c}\text { Promedio } \\
\text { Inferior }\end{array}$ \\
\end{tabular} & $\begin{array}{l}\text { Promedio } \\
\text { superior }\end{array}$ \\
\hline \multirow[t]{2}{*}{1} & Rojo & 21.08 & 18.67 & 23.50 & 32.77 & 28.65 & 36.90 & $6,852.94$ & $6,476.47$ & $7,229.41$ \\
\hline & Verde & 21.08 & 18.17 & 24.00 & 47.71 & 43.26 & 52.16 & $8,032.35$ & $7,617.65$ & $8,447.06$ \\
\hline \multirow{2}{*}{2} & Infrarrojo Cercano & 16.50 & 14.50 & 18.50 & 16.34 & 14.71 & 17.97 & $6,685.71$ & $6,264.29$ & $7,107.14$ \\
\hline & Verde & 31.38 & 27.75 & 35.00 & 57.43 & 51.85 & 63.01 & $9,196.43$ & $8,714.29$ & $9,678.57$ \\
\hline \multirow{3}{*}{3} & Infrarrojo Cercano & 22.17 & 18.33 & 26.00 & 23.41 & 17.32 & 29.50 & $8,131.25$ & $7,237.50$ & $9,025.00$ \\
\hline & Rojo & 39.33 & 34.33 & 44.33 & 68.73 & 53.14 & 84.32 & $10,212.50$ & $9,712.50$ & $10,712.50$ \\
\hline & Verde & 42.50 & 38.33 & 46.67 & 77.36 & 67.75 & 86.96 & $10,362.50$ & $10,050.00$ & $10,675.00$ \\
\hline
\end{tabular}

Para el error del scan line corrector para las escenas provenientes del satélite Landsat 7 se estimaron los límites de cada categoría de las zonas sin información visualizando la tendencia con apoyo de las franjas visibles. Afortunadamente el ancho de las bandas sin información no es lo suficientemente grande como para imposibilitar la tendencia del límite de la categoría identificada.

Para extraer las plumas de detritos suspendidos, se eliminó de cada escena la superficie continental utilizando como límite de costa el límite estatal 2010 de INEGI con un buffer o área de influencia de acuerdo al tamaño de pixel de cada imagen para garantizar la no interferencia de la porción continental en la clasificación. Una vez obtenida sólo la parte de mar en cada escena (Figura 3), por medio de la técnica de clasificación no supervisada se creó una máscara de filtrado con base a todos aquellos pixeles con alta reflectividad correspondientes a zonas cubiertas con nubes o errores radiométricos para posteriormente eliminarlos de la imagen.

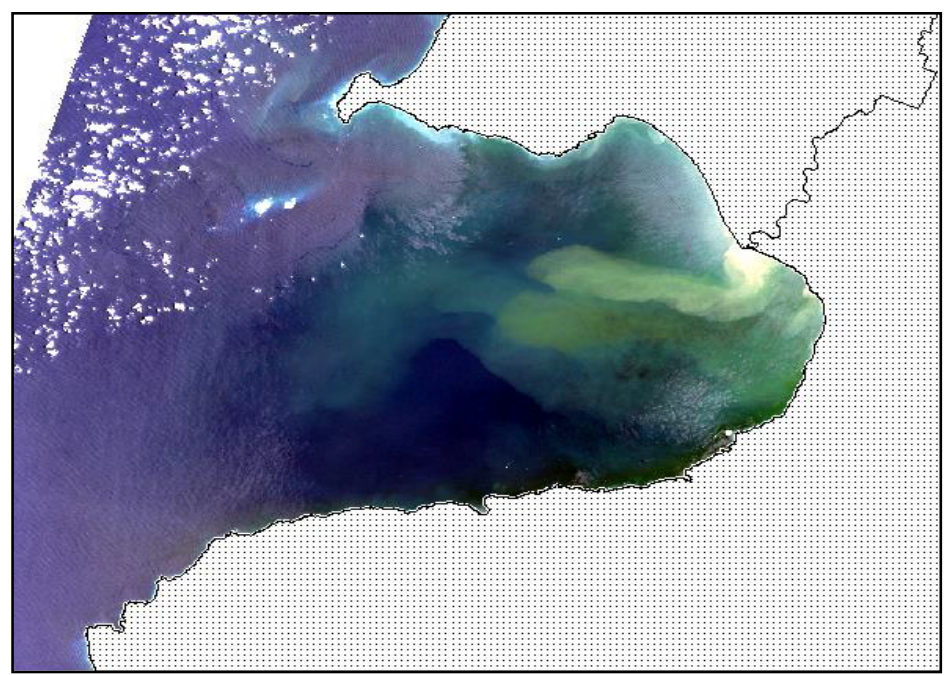

Figura 3. Escena sin el ruido radiométrico de la parte continental y nubes. 
Una vez con la imagen sin la parte continental y sin el error radiométrico de las nubes, se corrió nuevamente el algoritmo de la clasificación no supervisada utilizando todas las bandas de la escena para obtener un archivo dividido en distintas superficies (clases) de las cuales se vectorizaron sólo las correspondientes a las plumas de detritos (Figura 4).

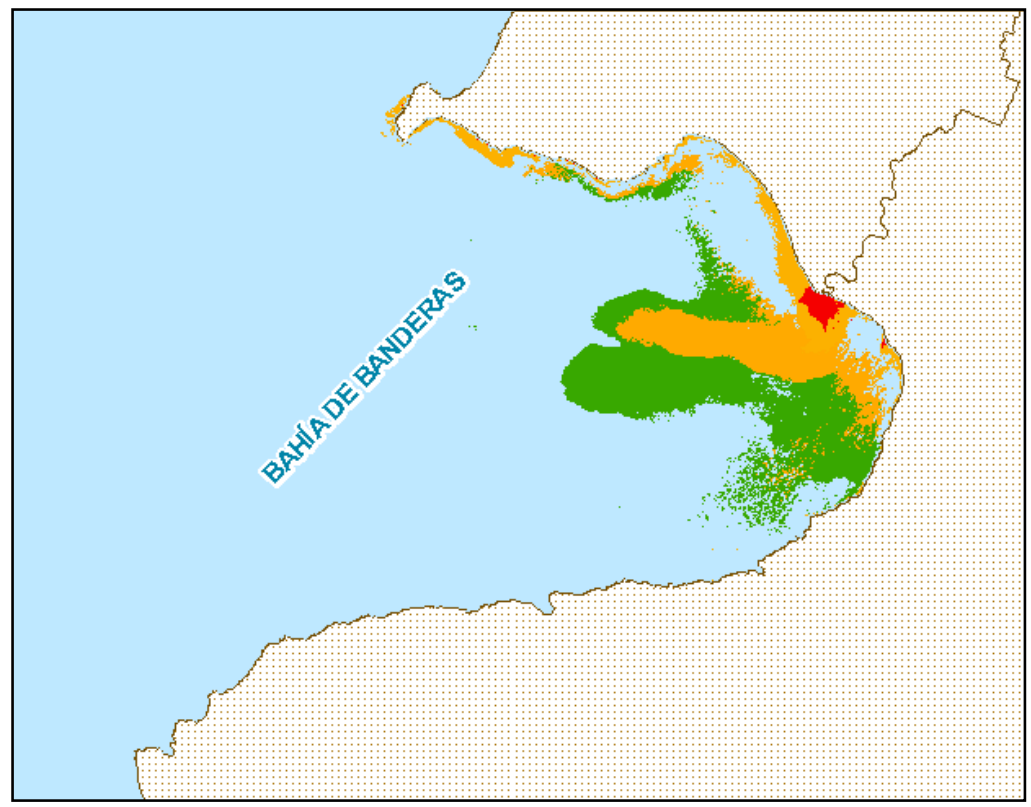

Figura 4. Pluma de detrito vectorizada. Rojo alta concentración, naranja concentración media y verde pluma difuminada o en proceso de sedimentación.

Se identificaron tres tipos de plumas según la concentración de partículas suspendidas y se establecieron fronteras radiométricas para cada categoría y sensor con la finalidad de hacerlas comparables a través de todo el periodo. Para representar el promedio de la superficie de la bahía cubierta por plumas se diseñaron cinco categorías $(1,1.01-1.50,1.51-2.00,2.01-2.50$ y $2.51-3.00)$ donde la primera es siempre dispersa y la última muy densa.

\section{Resultados}

Los resultados presentados no deben de considerarse como mapas de contaminantes ya que este trabajo no tuvo la intención de catalogar los tipos de contaminantes presentes en las plumas, sino más bien se deben de tomar como mapas de vulnerabilidad que hablan de las trayectorias promedio que puede seguir un supuesto contaminante en diferentes épocas. 
Aunque en la tesis se muestra un mapa con el promedio para cada mes de la distribución de detritos del periodo 2006-2014, en este artículo se nuestra solo el panorama del promedio anual pudiendo ver las zonas de mayor concentración de todo el periodo analizado (Figura 5).
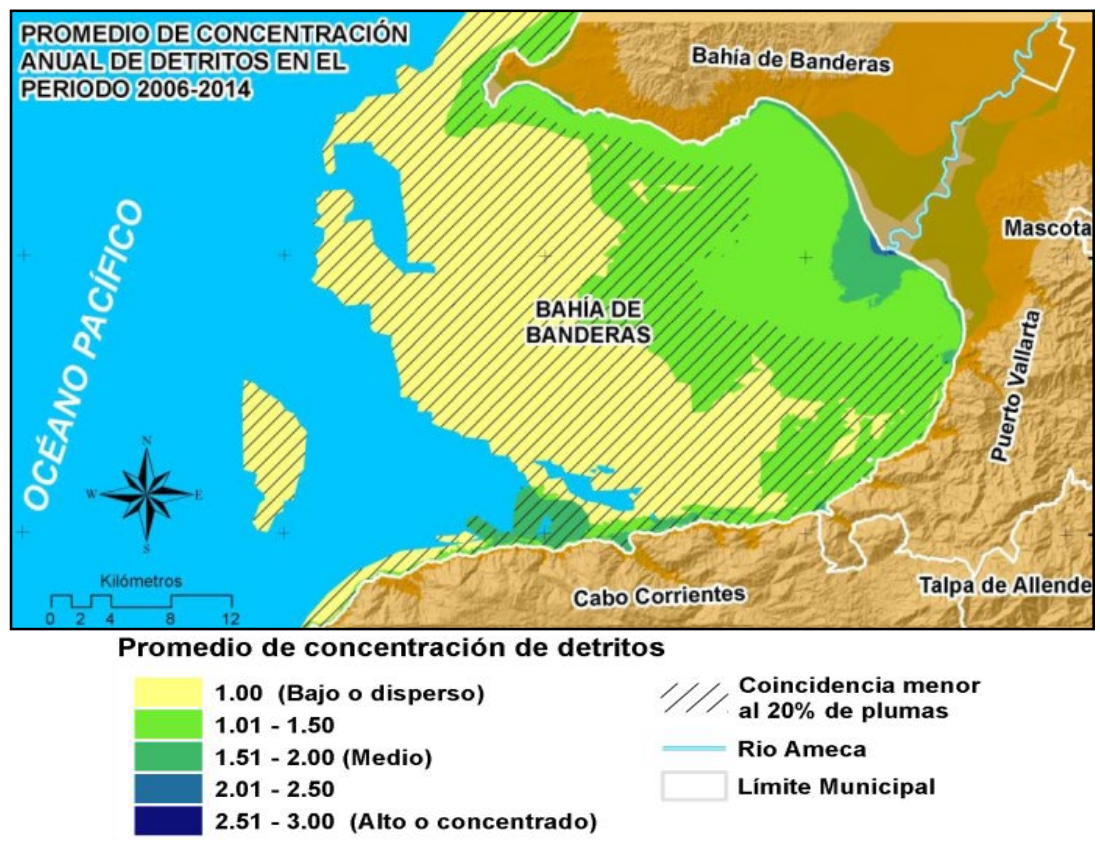

Figura 5. Pluma de detrito vectorizada. Rojo alta concentración, naranja concentración media y verde pluma difuminada o en proceso de sedimentación.

Un aspecto importante es que la mayor concentración de detritos suspendidos ocurre durante las primeras lluvias derivado a que en estas lluvias se arrastran los sedimentos y materia orgánica acumulados durante el periodo de secas.

En la Tabla 3 se muestra la comparación del caudal, precipitación y la concentración de plumas de detritos promedio por mes de todo el periodo en estudio. Marcado con verde se señalan los meses con el máximo de cada variable y con amarillo el mes con el segundo valor máximo de cada variable.

Como parte del análisis, se obtuvo la firma espectral de las tres concentraciones de sedimentos analizadas utilizando sólo las bandas 2, 3, 4, 5 y 6 de las escenas Landsat 8. Para las firmas espectrales se realizó un transepto iniciando en aguas sin sedimentos cruzando posteriormente mente zonas cubiertas por estos (Figura 6). 
Tabla 3

Comparativa del Caudal-Precipitación-Plumas promedio por mes (2006-2014)

\begin{tabular}{|l|c|c|c|c|}
\hline \multicolumn{1}{|c|}{ MES } & $\begin{array}{c}\text { Caudal Promedio } \\
\left(\mathbf{m}^{\mathbf{3}} \mathbf{s}\right)\end{array}$ & $\begin{array}{c}\text { Precipitación } \\
\text { Promedio } \\
(\mathbf{m m} / \text { día) }\end{array}$ & $\begin{array}{c}\text { Tamaño Total de } \\
\text { la Pluma }\left(\mathbf{k m}^{2}\right)\end{array}$ & $\begin{array}{c}\text { Tamaño de la Pluma superior } \\
\text { al 2\% de concentración }\left(\mathbf{k m}^{2}\right)\end{array}$ \\
\hline Enero & 4.740 & 0.940 & 549.000 & 0.000 \\
\hline Febrero & 2.330 & 1.518 & 364.340 & 0.000 \\
\hline Marzo & 1.460 & 0.025 & 255.900 & 0.000 \\
\hline Abril & 0.860 & 0.014 & 257.300 & 0.000 \\
\hline Mayo & 1.270 & 0.359 & 248.390 & 1.430 \\
\hline Junio & 5.570 & 5.826 & 545.570 & 29.420 \\
\hline Julio & 17.650 & 9.479 & 672.830 & 9.710 \\
\hline Agosto & 20.360 & 10.104 & 769.050 & 19.878 \\
\hline Septiembre & 32.830 & 8.662 & 792.650 & 24.200 \\
\hline Octubre & 16.340 & 3.333 & 497.280 & 4.920 \\
\hline Noviembre & 8.800 & 0.785 & 430.177 & 0.256 \\
\hline Diciembre & 5.550 & 0.836 & 308.480 & 0.000 \\
\hline
\end{tabular}

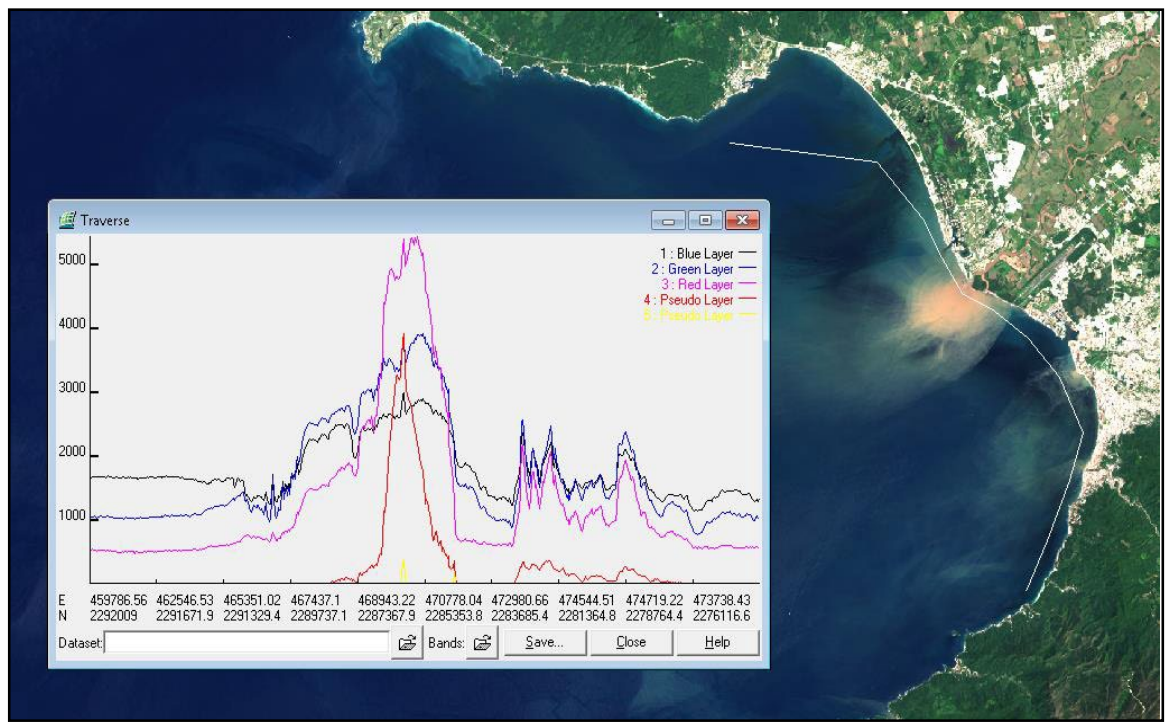

Figura 6. Firma espectral sobre imágenes Landsat 8 en puntos sobre agua de mar relativamente pura.

Para el primer caso (Figura 7), se muestran los valores de agua de mar relativamente pura extraídos de las imágenes. La mayor reflectividad en este punto ocurre en el color azul seguido por el verde y rojo; el infrarrojo cercano e infrarrojo medio tienen valores nulos. La forma de la firma espectral coincide con la del agua clara. 


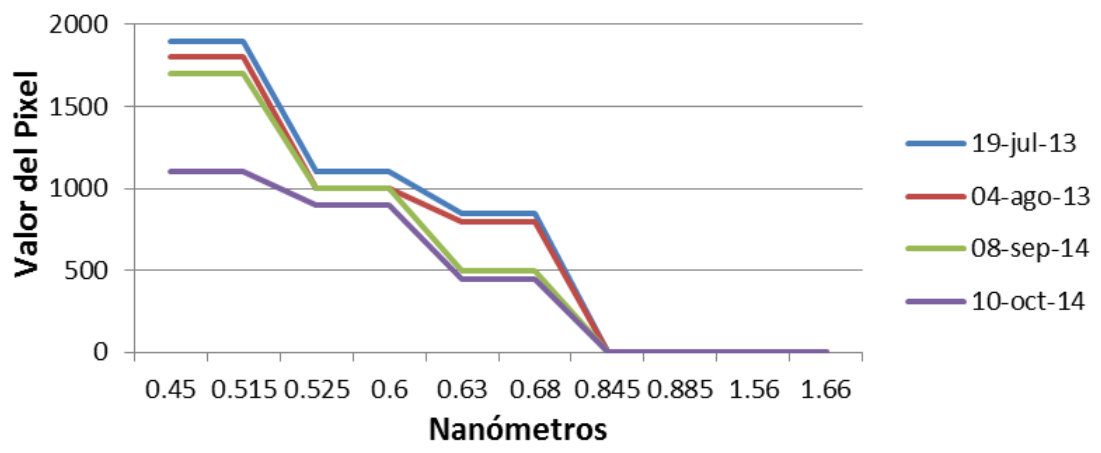

Figura 7. Firma espectral sobre imágenes Landsat 8 en puntos sobre agua de mar relativamente pura.

Para el segundo caso (Figura 8), la firma espectral sobre el agua de mar con concentración de categoría 2 de partículas suspendidas tiene mayor reflectividad en el verde seguido por el azul y el rojo. Sin embargo, aunque el verde y el azul predominan, vemos que el rojo tiene un crecimiento más marcado al ir aumentando la concentración de partículas suspendidas. Vemos también que la reflectividad del infrarrojo cercano e infrarrojo medio empieza a incrementarse aunque de forma muy lenta, lo que infiere la transición a agua turbia.

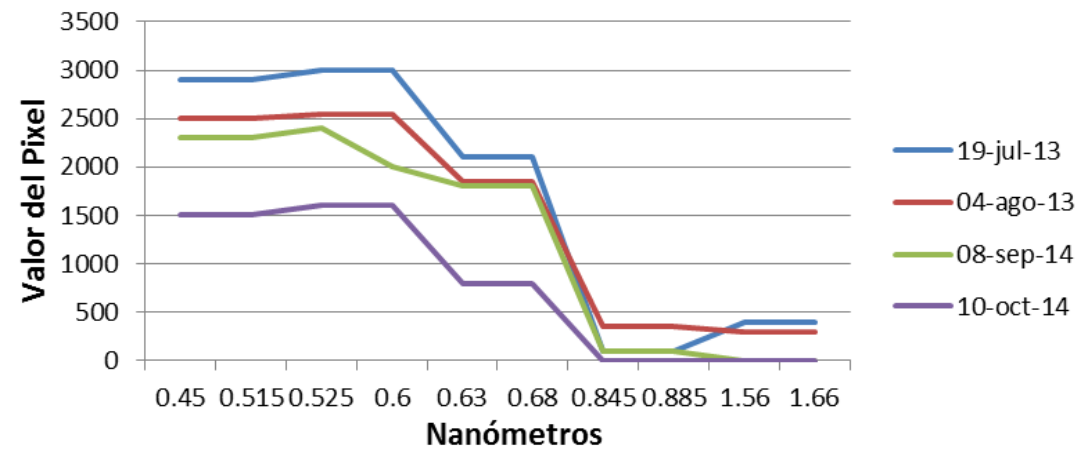

Figura 8. Firma espectral sobre imágenes Landsat 8 en puntos sobre agua de mar con concentración regular de partículas suspendidas.

Para el tercer caso (Figura 9) correspondiente a aguas con alta densidad de partículas suspendidas (categoría 3), la mayor respuesta espectral ocurre en el rojo seguido por el verde, infrarrojo cercano, azul y, finalmente, el infrarrojo medio; similar al del agua turbia. 


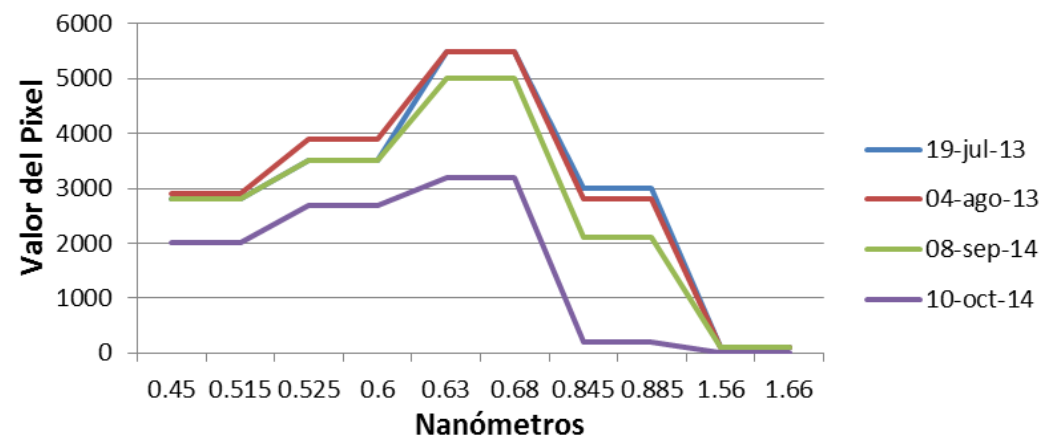

Figura 9. Firma espectral sobre imágenes Landsat 8 en puntos sobre agua de mar con alta concentración de partículas suspendidas.

Durante esta investigación se observó que la dirección de los detritos suspendidos no corresponde a la dirección del viento pues estos tienen una dirección predominante siempre hacia norte variando solo la intensidad; la dinámica corresponde a otros factores internos como las corrientes geostróficas o remolinos sub-superficiales. En el trabajo de realce de imágenes Landsat, fue posible visualizar en dos de ellas el remolino interno que, aunque es tema para otra investigación, parece ser el responsable del desplazamiento hacia el norte de los detritos suspendidos (Figura 10).

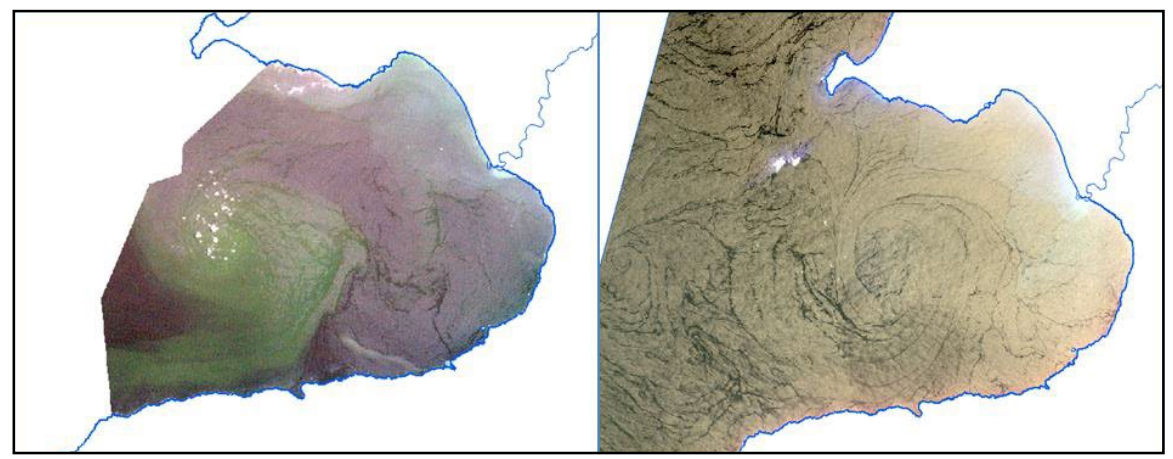

Figura 10. Remolinos ciclónicos internos. Arriba a la derecha corresponde al 19 de junio de 2008 del sensor Landsat 5 y a la izquierda del 04 de junio de 2014 del sensor Landsat 8 respectivamente.

\section{Discusión y conclusiones}

De acuerdo al análisis espectral de las imágenes de satélite y el análisis estadístico de la información vectorizada, se pudo detectar la tendencia de movimiento y concentración de las partículas suspendidas en la Bahía de Banderas. 
Fue posible identificar o dividir en tres rangos, con base a la respuesta espectral, distintas concentraciones de las partículas suspendidas. Al sobreponer todas las plumas detectadas, y obtener un promedio por cada mes considerando los distintos rangos, durante todo el periodo de estudio, se pudo establecer tendencias de concentración para cada uno de los meses.

Los tres meses con mayor presencia de partículas y, que a la vez muestran las mayores concentraciones, corresponden a septiembre, agosto y julio. Así mismo, se observó que el mes con mayor caudal coincide con el mes donde se registran las mayores plumas mientras que el mes donde se registran las mayores precipitaciones coincide con el segundo mes de mayores plumas detectadas.

Se concluyó también que Las plumas del mes de agosto parecen responder al agua precipitada directamente sobre el cauce y a las escorrentías superficiales que alimentan a estos ríos mientras que, las grandes plumas del mes de septiembre donde las precipitaciones no presentan su máximo, parecen responder más a la aportación hacia los ríos de las grandes cantidades de agua precipitada en los meses anteriores incluyendo las del mes de agosto y almacenadas en los mantos freáticos que, junto con las lluvias propias del mes de septiembre, generan las mayores plumas registradas en el año.

La anterior hipótesis puede ser un tema de investigación en donde se deben involucrar mediciones en periodos lluviosos de mantos freáticos, represas entre otros y analizar más a detalle esta relación.

Por otra parte, se observó que gran parte de las partículas suspendidas tienden a desplazarse hacia la parte norte, pegados a la costa del municipio de Bahía de Banderas, para posteriormente salir a mar abierto mientras que, otra parte se sedimentan en el fondo de la bahía antes de que puedan salir a mar abierto.

Las imágenes de satélite nos muestran que las mayores concentraciones de detritos solo se presentan en promedio en el año alrededor de la desembocadura del Río Ameca disminuyendo su concentración conforme se alejan de este punto. La parte sur de la bahía parece estar casi siempre libre de la presencia de estos detritos mostrando solo bajas concentraciones en eventos de precipitaciones aisladas.

Se observa que el viento no tiene relación con la dirección de las pumas ya que es frecuente ver que la dirección observada de las plumas no siempre coincide con la dirección del viento aunado a que existen días donde no se registra viento y la pluma conserva la dirección de movimiento hacia el norte. Por lo anterior se deduce que el movimiento de las plumas es causado por fuerzas oceánicas como las corrientes, ondas o remolinos internos los cuales, estos últimos, se detectaron a través de un realce de falso color de escenas multiesprectrales del satélite Landsat.

Por último, debido a la información y correlación obtenidas, es posible utilizar la presente metodología a otras regiones del mundo ya que el presente trabajo también utilizo de referencia otros estudios previos los cuales dieron resultados certeros. Se 
recomienda la utilización de imágenes multiespectrales con mejor resolución espacial o la utilización de sensores multiespectrales en drones para lograr datos más finos los cuales siempre tienen que estar validada con algunas mediciones insitu si lo que se desea es también inferior la composición de los residuos suspendidos.

\section{Bibliografía}

Acker, J., Ouillon, S., Gould, R. and Arnone, R. (2005). Measuring Marine Suspended Sediment Concentrations from Space: History and Potential, International Conference on Remote Sensing for Marine and Coastal Environments, Halifax, NS, Canada.

CEDESTUR-CEED-AEBB (2001). Bahía de Banderas a futuro: 2000-2005, Centro de Estudios Estratégicos para el Desarrollo Turístico Sostenible, Technical Report, Asociación de Empresarios de Bahía de Banderas, Puerto Vallarta.

Del Castillo, C.E., F. Gilbes, P.G. Coble and F.E. Muller-Karger (2000). "On the Dispersal of Riverine Colored Dissolved Organic Matter (CDOM) over the West Florida Shelf”, Limnology and Oceanography, 45(6):1425-1432.

Ekercin, S. (2007). "Water Quality Retrievals from High Resolution IKONOS Multispectral Imagery: A Case Study in Istanbul, Turkey”, Water Air Soil Pollut, 183:239-251.

Filonov, A.E. (2010). Circulación y Transporte de Contaminantes Pasivos en la Bahía de Banderas, Jalisco-Nayarit, México. Reporte Técnico Final, COECyTJal.

García, M.P. and Pérez, M.E. (1999). Estudio mediante imágenes TM del entorno de Villacañas (Toledo), Revista de Teledetección, no. 11, pp. 13-22.

$\mathrm{Hu}$, C., E.T. Montgomery, R.W. Schmitt and F.E. Muller-Karger (2004). "The dispersal of the Amazon and Orinoco River water in the tropical Atlantic and Caribbean Sea: Observation from space and S-PALACE floats", Deep Sea Research Part II: Topical Studies in Oceanography, 51(10-11):1151-1171.

Kelly Liza (2010). "Variación espacio temporal de la calidad del agua en la zona de mayor influencia continental en la Bahía de Banderas, México", tesis de doctorado, Centro Universitario de la costa, Universidad de Guadalajara, Puerto Vallarta, Jalisco, México.

Knaeps, E.; Sterckx, S. and Raymaekers, D. (2010). “A Seasonally Robust Empirical Algorithm to Retrieve Suspended Sediment Concentrations in the Scheldt River", Remote Sensing, 2:2040-2059.

Lohrenz, S.E., Dagg, M.J. and Whitledge, T.E. (1990). "Enhanced primary production at the plume/oceanic interface of the Mississippi River", Continental Shelf Research, 10:639-664. 
Miller, R.L. and B.A. Mckee (2004). "Using MODIS Terra 250 m Imagery to Map Concentrations of Total Suspended Matter in Coastal Waters", Remote Sensing of Environment, 93:259-266.

Mireles, L.I.O. (2012). "Estructura Termohalina y Circulación Geostrófica en Bahía de Banderas, Jalisco-Nayarit, México", tesis de maestría Ciencias en Hidrometeorología, Departamento de Física, Centro Universitario de Ciencias Exactas e Ingenierías División de Ciencias Básicas, Universidad de Guadalajara, Guadalajara, Jalisco, México.

Muller-Karger, F.E. and R. Varela (1990). "Influjo del río Orinoco en el mar Caribe: Observaciones con el CZCS desde el espacio", Mem. Soc. Cien. Nat., La Salle, 131-134:365-384.

Muller-Karger, F.E.; C.R. McClain, T.R. Fisher, W.E. Esaias and R. Varela. (1989). "Pigment distribution in the Caribbean Sea: observations from the space", Progress in Oceanography, 23:23-69.

Muller-Karger, F.E., P.L. Richardson and D. McGillicuddy (1995). "On the offshore dispersal of the Amazon's Plume in the North Atlantic", Deep-Sea Research I, 42(11/12):2127-2137.

Pérez, B.D. y Nadja, O.C.F. (2011). “Comparación de la dinámica de sedimentos suspendidos entre una bahía tropical abierta y una bahía tropical cerrada”, Departamento de Física y Departamento de Geología, Universidad de Puerto Rico, Recinto Universitario de Mayagüez, Puerto Rico, pp. 15-16.

Plata, L.J. (2007). "Dinámica de las Ondas Internas en la Bahía de Banderas, JaliscoNayarit, México", tesis doctoral, Facultad de Ciencias Marinas, Instituto de Investigaciones Oceanológicas, Universidad Autónoma de Baja California, 152 pp.

Ritchie, J.C. and Cooper, C.M. (2001). "Remote Sensing Techniques for Determining Water Quality: Applications to TMDLs", in TMDL Science Issues Conference, Water Environment Federation, Alexandria, VA, pp. 367-374.

Ritchie, J. and F. Schiebe (1986). "Monitoring Suspended Sediments with Remote Sensing Techniches2, Hydrologic Applications of Space Technology, pp. 233243.

Rodríguez, G.V. and F. Gilbes S. (2009). "Using MODIS 250 m Imagery to Estimate Total Suspended Sediment in a Tropical Open Bay”, International Journal of Systems Applications, Engineering \& Development, 3(1):36-44.

Salinas, G.F. y Pinet, P.R. (1991). Corrientes Geostróficas frente a Bahía Magdalena Baja California Sur, México, CICIMAR, vol. 6, núm. 2.

\section{Referencias Digitales}

Aguaysig (2012). Descargar imágenes Landsat de USGS. Recuperado de: $<$ http://www.aguaysig.com/2012/05/descargar-imagenes-landsat-de-usgs.html $>$. 
Carmen González Toro, octubre 2011, Monitoreo de la calidad del agua, La turbidez. Servicio de extensión agrícola, Colegio de Ciencias Agrícolas, pp. 2-6. $<$ http://academic.uprm.edu/gonzalezc/HTMLobj-859/maguaturbidez.pdf $>$.

Centro de Estudios Meteorológicos de la Costa (2016). "Estaciones Meteorológicas en Tiempo Real". Recuperado de: <http://cemco.org.mx/>.

Comisión Nacional del Agua (CNA) (1998). "Cuencas Hidrológicas (CNA)". Recuperado de: <http://www.conabio.gob.mx/informacion/gis/?vns=gis_root/hidro/chidro/rh250kgw $>$.

(2015). Atlas Digital del Agua México 2012. Recuperado de: $<$ http://www.conagua.gob.mx/atlas/ciclo09.html $>$.

Earthdata, NASA (2015). Rapid Response / Earthdata (descarga de imágenes de satélite MODIS). Recuperado de: <https:/earthdata.nasa.gov/earth-observationdata/near-real-time/rapid-response $>$.

El Informador (2008). "Ríos contaminan playas en Bahía de Banderas", Recuperado de: <http://www.informador.com.mx/jalisco/2008/7414/1/rios-contaminan-playas-en-bahia-de-banderas.htm $>$.

Estrucplan On Line (2015). "La contaminación del Río Ameca y su impacto en la salud". Recuperado de: <http://www.estrucplan.com.ar/articulos/verarticulo.asp?IDArticulo $=2235>$.

Pro.arcgis (2015). Clasificación no supervisada de cluster ISO_Ayuda | ArcGIS for Desktop. Recuperado de: <http://pro.arcgis.com/es/pro-app/tool-reference/spatial-analyst/iso-cluster-unsupervised-classification.htm $>$

SEMARNAT (2015). Programa de Playas Limpias, Puerto Vallarta/Bahía de Banderas, Jalisco. Recuperado de: <http://www.semarnat.gob.mx/playas/playas_limpias/destinos/puerto-vallarta $>$. 